
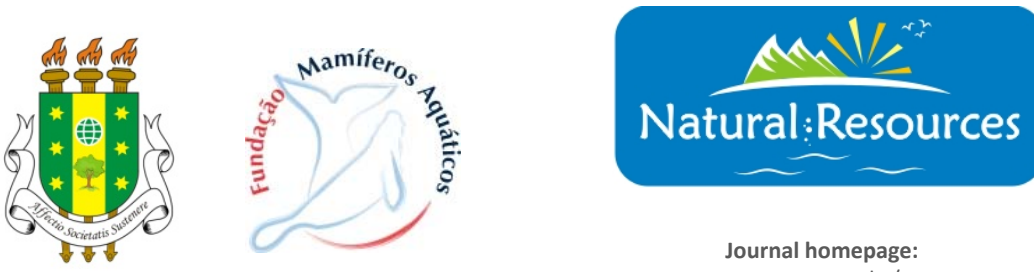

Journal homepage:

www.arvore.org.br/seer

\section{USO DE ACAJU MEMBRANA EM PACIENTES ACOMETIDOS POR ÚLCERA VARICOSA}

\section{RESUMO}

As plantas medicinais sempre estiveram presentes na prevenção e no tratamento das doenças, porém, associadas a rituais místicos. Não é possível precisar o tempo exato da utilização desses meios de tratamento. A úlcera por pressão é definida como uma área localizada de morte celular, que se desenvolvem quando um tecido mole é comprimido entre proeminência óssea e uma superfície dura por um longo período de tempo. O presente estudo tem como objetivo conhecer a extensão de trabalhos produzidos com abordagem do uso de Acajumembrana, Materiais. Levantamento bibliográfico realizado na Faculdade de Enfermagem São Vicente de Paula, Universidade Federal da Paraíba, Centro de Defesa do Saber Popular de Saúde. A partir daí averiguamos que utilização de um curativo com uma membrana, denominada de acajumemembrana que é uma membrana fitoterápica de uso tópico desenvolvida a partir do sumo fermentado do pseudofruto de Anarcadiumoccidentale L., identificada como levedura - Pichiamembranaefaciens E. C. Hansen pelo Instituteofthe Royal NetherlandsAcademyofArtsandSciences. Apresenta na sua composição fitoquímica fenóis, taninos, flavonas, flavonóis e xantonas. É indicada para o uso tópico em feridas crônicas, micose, que possui ação antiinflamatória e cicatrizante É puramente fitoterápico, sem possuir qualquer aditivo ou modificações químicas e que, em contato com a pele, propicia a liberação lenta e gradual dos constituintes nela contidos, favorecendo a regeneração dos tecidos destruídos pelo processo inflamatório. Propriedade farmacológica é atribuída a casca de Anarcadiumoccidentale L, com efeitos terapêuticos como: aliviar a dor de dente, anti-inflamatório para gengiva e garganta, bronquites, artrites, anti-hemorróidicos,cólicas intestinais, icterícia, diabetes, asma, antitussígena, antisifílica, diurética, colutória. Segundo estudos realizados, a existência de taninos na casca em proporção de 11,2 vezes mais eficaz que a dipirona, apresentando uma atividade anti-inflamatória e analgésica. Resultados, Segundo estudo realizado em três municípios de João Pessoa,com 21 pacientes acometidos por úlcera varicosa, onde em seu tratamento foi usado Acajumembrana, tendo êxito em todos os curativos. Refere-se ainda em outro estudo que, em 2 pacientes acometidos de pé diabéticos,com intervenção em trinta dias de curativos com acajumembrana, obtiveram uma melhora acentuada no processo cicatricial, aumento do tecido epitelial e redução total do tecido desvitalizado. Aponta-se que a troca do curativo convencional pelo curativo artesanal de acajumembrana, teve uma redução significativa de custo. O paciente faz troca diária de curativos, portanto faz uso de 28 a 31 membranas mensalmente; Considerando o valor máximo da membrana, os custos ficam em torno de $R \$ 0,60 \times 30$ dias=R $\$ 18.00$ e lou $R \$ 0,60 \times 31=R \$ 18,60$, por paciente por mês. Os outros custos do curativo são decorrentes da utilização da gaze,luva de procedimento e atadura de $10 \mathrm{~cm}$. O resultado desta relação mostra, segundo estudo, que o curativo da acajumembrana equivale a $47,19 \%$ do custo do curativo convencional e que esta nos mudanças nos procedimentos realizados na Associação Promocional do Ancião resultou em uma economia de $52,81 \%$ nos custos dos curativos. Considerando apenas a membrana com máximo custo e a pomada mais barata, a Associação Promocional do Ancião obteve uma economia de 89,77 \% Esta relação de custo é relativa somente ao curativo e não inclui custos indiretos como os da utilização de anti-inflamatórios,analgésicos e antitérmicos, frequentes quando da utilização do curativo convencional. Conclusão. Desta forma, é necessário que os profissionais de saúde tenham conhecimento sobre úlcera varicosa, os fatores de risco que levam à incidência e a prevalência, a fim de implementarem um programa de melhoria da qualidade da assistência com ações eficazes de prevenção e tratamento. Essa intervenção terapêutica é de baixíssimo custo, simples de usar, e de fácil acesso a matéria prima para obtenção da Acajumembrana, essa terapêutica produz uma sensação de conforto com a redução da dor, ardor e queimor das úlceras; consequentemente, ajuda na prevenção do sono dos pacientes; Esses dados reforçam ainda mais as vantagens deste novo recurso fitoterápico.

PALAVRAS-CHAVE: Úlcera por Pressão; Acajumembrana; Assistência de Enfermagem.
Natural Resources, Aquidabã, v.3, n.2, Set 2013.

ISSN 2237-9290

\section{SECTION: Anais do Congresso Internacional de Ecotoxicologia Marinha (ECOMAR 2013)}

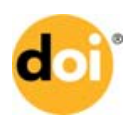

DOI: 10.6008/ESS2237-9290.2013.002.0013

Cleonice Oliveira dos Santos

Faculdade São Vicente de Paula, Brasil oliveira cleonice@hotmail.com

Maria da Salete Horácio da Silva

Centro de Defesa do Saber Popular em Saúde, Brasil http://lattes.cnpq.br/9946387390285306 mshsilva@gmail.com

Received: 01/04/2013

Approved: 15/06/2013

Reviewed anonymously in the process of blind peer.

Referencing this:

SANTOS, C. O., SILVA, M. S.. Uso de acaju membrana em pacientes acometidos por úlcera varicosa. Natural Resources, Aquidabã, v.3, n.2, p.18, 2013. DOl: http://dx.doi.org/10.6008/ESS2237$\underline{9290.2013 .002 .0013}$ 